\section{"Whistling Face" Deformity in Compound Cranio-facio-corporal Syndrome}

British Medical Fournal, 1970, 4, 33

We report a case with an unusual combination of multiple congenital deformities, one of which, the "whistling face" deformity, is extremely rare. The face appears stiff, immobile, and masklike, but no solid mass of muscle is palpable in the buccal region. Burian (1963) reported four cases of a compound cranio-facio-corporal syndrome, but there do not appear to be any other similar reports in the literature.

\section{Case History}

The patient, a boy aged 3 years, was brought to the outpatient department by his father on 6 November 1968 because he was unable to open his mouth wide enough to take solid food. The condition had been present since birth and he had been nourished

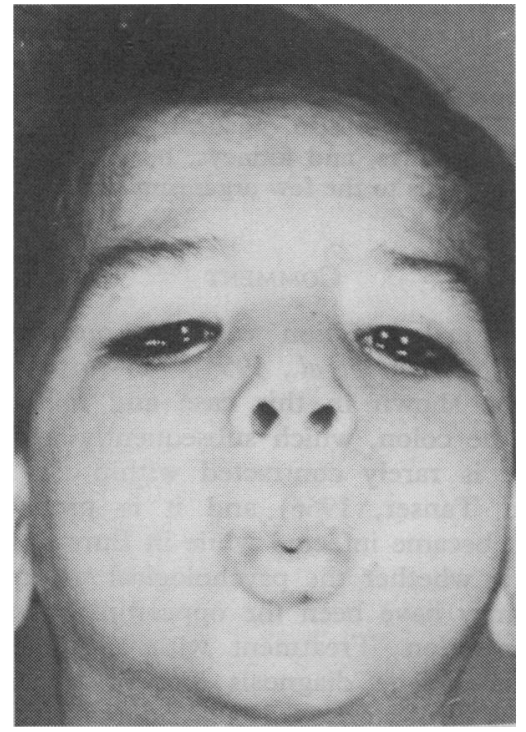

Fig. 1.
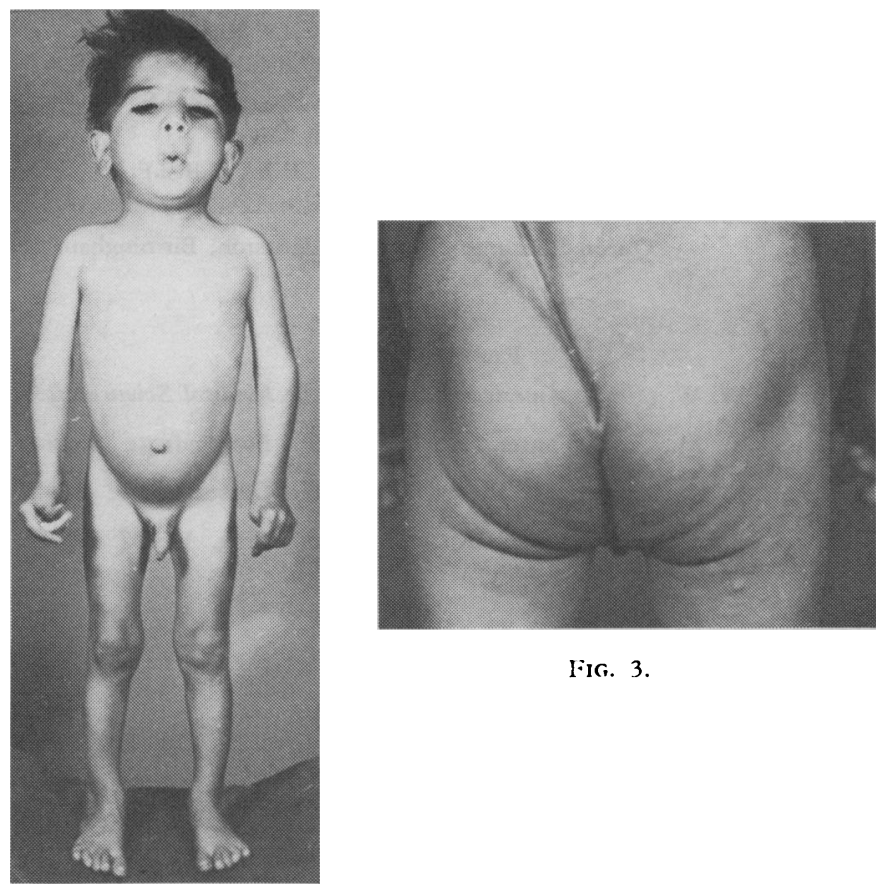

Fig. 3. on fluids only. He had been delivered normally at full term, but his mouth was apparently closed by a "membrane." This was removed by a local "medicine man," revealing a narrow mouth opening. The child had puckered lips, which did not relax even during sleep.

Examination showed him to be thin and small for his age. His face looked stiff, immobile, and masklike (Fig. 1). The transverse opening of the mouth was $20 \mathrm{~mm}$. only. There were no scars on the lips, which protruded as in whistling. No muscle mass in the lips or the cheeks could be felt. The palate was high-arched. Speech was unclear and nasal. The teeth were normal for his age. $\mathrm{He}$ also had epicanthus and ptosis of both eyelids; alae nasi directed downwards and backwards, with the columella descending backwards to join the upper lip at an obtuse angle; a short, broad neck; ulnar deviation of the third, fourth, and fifth fingers at the metacarpophalangeal joints with contracture of the thumb in adduction in both hands; medial rotation of the third and fourth toes at the metatarsophalangeal joints in the feet; and a postanal dimple (Figs. 2 and 3).

Despite his nasal speech he communicated easily and appeared to be normally intelligent. Electromyographic studies showed minimal activity of the buccinator muscle but normal activity of other facial muscles. Biopsy of the buccinator muscle revealed atrophic muscle fibres.

Operation was undertaken for his puckered mouth. The angles of the mouth were opened by slitting them horizontally after drawing a vertical line from the medial edge of the pupils. The mucosa was advanced outwards and stitched with skin by interrupted chromic catgut sutures. On discharge he was able to open his mouth sufficiently to take solid food.

\section{R. N. SHARMA, M.S., F.R.C.S. \\ S. N. TANDON, ${ }^{*}$ M.B., B.S., M.S.}

King George V Medical College, University of Lucknow, India. *Present appointment: Registrar, Plastic Surgery and Burns Unit, Bangour General Hospital, Broxburn, West I.othian, Scotland.

REFERENCE

Burian, F. (1963). British Fournal of Plastic Surgery, 16, 140.

\section{Case of Disseminated Histoplasmosis}

British Medical fournal, 1970, 4, 33-34

Disseminated histoplasmosis rarely causes death, even where the disease is endemic (Addington, 1967). Six cases only of disseminated histoplasmosis have been reported previously in the United Kingdom (Partridge and Tanser, 1966).

\section{CASE History}

A 63-year-old Caucasian man was first seen as an outpatient in August 1963. He complained of loose and explosive bowel actions for the previous eight months. Before the onset of this disorder he had been fit and well, except for two previous attacks of gastroenteritis, one in 1946, when returning from Burma by troop-ship, and one in 1962, when clinical examination and sigmoidoscopy were negative. A barium enema showed diverticula in the sigmoid colon but no other abnormality. His symptoms then remitted and he remained well until the winter of 1967, when he began to lose weight. At this time he had some personal problems and was drinking heavily and eating little. He was seen again in September 1968 complaining of a 4-st. (25$\mathrm{kg}$.) weight loss over a period of nine months, six weeks' anorexia and constipation, bilateral ankle swelling, and lassitude of three weeks' duration. On examination he was pale, wasted, and had hepatosplenomegaly and bilateral ankle oedema, more on the right than on the left. There was no lymphadenopathy.

He was admitted to hospital and found to have a hypochromic anaemia. Haemoglobin $10.5 \mathrm{~g} . / 100 \mathrm{ml}$. White cell count and differential normal. E.S.R. $8 \mathrm{~mm}$. per hour. Biochemical studies were not informative. Stool, urine, serum, and a chest $x$-ray picture were normal. Barium meal and follow-through examination 